\title{
21
}

\section{Critiques of the Neurodiversity Movement}

\author{
Ginny Russell
}

\section{Preamble}

I am going to recount some of the main reproaches to the movement, as I understand them, and show how these are sometimes answered or addressed by our contributors. This does not claim to be a "comprehensive" account of critiques, as my knowledge of the movement is incomplete, and like others' understandings, my writing is situated by and limited by my own reading and experiences [1]. Nevertheless, I believe it is important to be aware of critiques, to engage with criticism, and openly debate, defend, or modify one's position, in both the political and academic spheres.

The start of my chapter concerns critiques that apply to identity politics more broadly: that they dichotomize allied groups into factions (this prevents smaller identity groups from linking up, causing rivalries and discord). Sociologist Charles Derber asserts that identity politics does not include a broad critique of the political economy of capitalism, instead

\footnotetext{
G. Russell ( $\varangle)$

College of Medicine and Health/College of Social Science and International Studies, University of Exeter, Exeter, UK e-mail: g.russell@exeter.ac.uk 
focusing on reforms. In a version of "divide and rule" argument he suggests that fragmented and isolated identity movements have allowed for a far-right resurgence [2]. There is also friction within identity politics over definitions of who is included as "in" a particular group. The main critiques of the neurodiversity movement are then listed as follows: first, the movement has been accused of being unrepresentative of all people who are "neurodivergent," and specifically unrepresentative of more impaired people on the autism spectrum (a criticism made by some clinicians, autistic people, and parents). Second, it is said arguments made by the movement are reductionist, promoting a genetic/brain-based understanding of autism (a critique made by academics in social sciences, history, and philosophy of biology). This may deflect attribution of personal responsibility for behavior to the brain. Third, there is a criticism along the lines of the well-known declaration that "the master's tools will never dismantle the master's house" [3].

\section{How Identity Politics Dichotomizes Would-Be Allies}

Throughout this collection, contributors use the terms "neurotypical" and "neurodivergent" to denote two distinct groups. Accounts in this collection by Garcia, Neumeier and Brown, and Arnold, amongst others, utilize both terms. Disability scholar Runswick-Cole [4] has pointed out these terms can be divisive, fostering an "us" and "them" mentality. She denounces a dichotomized view of the world where you are either "in" or you are "out".

As we know from many studies of autism and other neurodevelopmental conditions, autism and other diagnostic classes are psychiatric constructs that denote a spectrum: a series of interrelated multidimensional traits. These extend into the subclinical population, therefore many people who do not have an autism diagnosis have autistic traits. This is known by researchers as the "broad autism phenotype" [5-7]. It means there is no clear bimodal distribution separating people with and without autism, so in reality there are not two distinct populations, one "neurotypical" and one "neurodivergent." Instead autistic traits are distributed normally in the whole human population [8], as are ADHD traits [9]. 
In addition, the tendency to dichotomize runs contradictory to the inclusive definitions of neurodiversity given in the book. DaVanport (Chapter 11) talks about neurodiversity thus: "Neurodiversity soon became something that I intimately understood as the all-inclusive acceptance of every neurological difference without exception. I further came to appreciate that neurodiversity didn't leave anyone out." Greenburg (Chapter 12) defines neurodiversity: "Neurodiversity in my world, is the unquestioned right for all, whatever their neurological makeup, to express what they need or want." She writes: "While I can't define the totality of Neurodiversity even for myself, much less anyone else, I know spaces where I can see it." At another point in her text, Greenburg puts the emphasis on difference, describing "non-autistics whose brains and experiences differ from ours so much" (Chapter 12).

"Neurotypical" (NT) is never used pejoratively in this collection. But in autism online commentaries and debates it has been suggested such critical language is justified by the poor treatment meted out to the autistic community (as well documented here). Tisoncik discusses "autistic superiority" (Chapter 5) which is the tendency to claim autistic people are in some way superior to NT people. She writes, "I am not upset about claims of autistic superiority," explaining that although this is not her position, "we don't need to worry about oppressed groups with little to no power singing their own exclusive praises." An example of such a claim comes from description of NTs from the forum Quora: "I'm being cruel I know. It's okay though they have all the power and they have discriminated against me all my life. I'm allowed to make fun of their innate stupidity...they expect everyone to know it because they are the center of the universe. Their hypocrisy on this is near universal" [10].

The issue with this is common to all identity politics and best explained by alluding to another movement- the feminist movement. The argument made is that it is fine to be pejorative about, or insulting to, people that profit from the status quo. But this is the same as a feminist saying pejorative things about men e.g. "all men are <insert pejorative/offensive word here >": a blanket dismissal of all men. Clearly, there are some men who are feminists and sympathetic to the aims of the feminist movement. Plus, many men have characteristics that mean they too are discriminated against: gay men, disabled men, migrants, and so on. To dismiss them all 
in a blanket way will have the effect of alienating them from the cause. To effect societal change, solidarity between such groups is vital, and those on the left seeking to rebalance the status quo need to support each other's struggles. In addition, "all men are <insert pejorative term here>" is itself a sexist statement. It is discriminatory to make offensive statements about the "out" group, where the struggle should be against discrimination and prejudice.

The true target for righteous anger, Runswick-Cole [4] and others have argued, should be discriminatory and disabling societal structures, norms, and practices. It is an issue many activists writing here seem well aware of. Seidel, for example, writes: "I felt that needless discord, demagoguery, and polarization could only exacerbate tensions and undermine advocacy efforts" (Chapter 7).

Standpoint theorists support the idea that people with lived experience have expertise in their own area [11]. This is the theoretical epistemic stance that underpins this volume. It assumes standpoints are relative and cannot be evaluated by any absolute criteria, but makes the assumption that the oppressed (autistic people) are less biased (or more impartial) than the privileged (NT people). This idea that people with lived experience should be given more authority to speak, and make decisions about their own futures, i.e. their voices should be given more weight than others, has been criticized. To illustrate, take the example of female genital mutilation (FMG), a practice widely abhorred. The main promoters of such practices are often the grandmothers of the girls involved who themselves have been subject to FGM. According to standpoint epistemology, such voices (calling for FGM) should trump those of Western medical experts.

Another critique of the NT/ND divide is that "Neurotypical" is a very dubious construct, and by default then so is "Neurodivergent." Is there anyone who is really, truly neurotypical? As Armstrong writes:

There is no such standard for the human brain. Search as you might, there is no brain that has been pickled in a jar in the basement of the Smithsonian Museum or the National Institute of Health or elsewhere in the world that represents the standard to which all other human brains must be compared. Given that this is the case, how do we decide whether any individual human brain or mind is abnormal or normal? [12] 
Of course, you do have to draw a line in the sand when you are demarking yourself into a politically mobilized group. That is, for the neurodiversity movement to exist there has to be a banner "Neurodivergent" under which people can rally. That is required by any group- that you can argue for rights for some people and not others, make the case for services for some people and not others. I will drop the quote marks around "Neurodivergent" for the remainder of this piece, as it is impossible to define an identity-based movement without having a group identity. In order to promote a positive self-identity too, you first need a group-based identity. I understand that. But it is helpful to be aware, in tandem with this, that dichotomizing can also cause difficulties.

\section{Defining Who Is "In": Who Is Neurodivergent?}

Another issue that applies to the whole of identity politics is the problem of definition of people in the category. It is not always clear from accounts in the book who is neurodivergent, and who is not. However, this is a crucial issue. If you are advocating for legal protection against discrimination, or arguing for support and accommodations, it is really important to be able to define who that group actually are. If you are not clear who exactly you are fighting for, those rights cannot be operationalized in law.

The nature of brain differences between autistic and non-autistic people is not well-established or well-replicated [13], and many neuroscientific studies of ADHD, Tourette, autism, and other neurodevelopmental conditions have mixed results that are not well-replicated. The reality is that most of these conditions are diagnosed via observation, cognitive testing, or self-report, and not via neurological anatomy or physiology. Not many diagnoses involve brain scans, so the neurological differences of neurodivergent people are not seen but inferred.

Perhaps who is "in" as neurodivergent (ND) could be decided by a medical diagnosis of a neurodevelopmental disorder, or a mental health condition that is thought to be underpinned by neurophysiology, like autism or depression? Neumeier and Brown seem to suggest this when 
they write that "neurodivergence [includes] psychiatric disability or mental illness" (Chapter 14). But the neurodiversity movement rallies against the "medical model" as Arnold describes it, explaining his journal's aim to "embody a questioning and examining of the prevailing paradigms of autism research" (Chapter 15). Then it is perhaps inappropriate to have group inclusion criteria defined by medical diagnosis. Such a definition would return the epistemic authority to define the group to medics, thus rescinding the notion of "Nothing About Us Without Us" quoted extensively by many contributors. Moreover, some people considered ND may not yet have been diagnosed.

Perhaps, then, self-identification as ND is less problematic? Giwa Onaiwu opted for this approach, "to accept the validity of people's selfidentification as stated," when compiling her intersectional anthology (see Chapter 18). Self-definition certainly avoids the problems listed above, but has caused huge divisions in other areas of identity politics. Arguments between radicals in the feminist movement and the transgender activists again provide an example. Some radical feminists have argued that being a woman should be defined by biological sex and being bought up female from birth, whereas the transgender activists have argued that anyone who self-identifies as female is female. The trans-excluding radical feminists assert that decades of rights they have fought for to have women-only safe spaces are now being undermined, if (wo)men who self-identify as women are now allowed into them. This issue was satirized in the UK by a Labour party member who previously made it onto the list of candidates for women's officer because he "identifies as a woman on Wednesdays," under Labour's "self-id" rules [14]. The man has now been suspended from the party.

Self-definition may also exclude some people, who may be part of the "in" group, but may not be aware of being in the group at all. For example, ND people with late-stage dementia, or profound intellectual disability. Others who may be ND don't want to be labeled as such. Activists writing in the collection seem aware of the potential complications arising from dividing people into well-defined groups, and several try to address the problem. For example, Buckle explains the decision for no inclusion criteria whatsoever at Autscape thus: 
Having inclusion criteria, e.g. "autistics only" creates suspicion about whether those in the group are really "us" or may be "them," whether deliberately (infiltrators) or by mistake (falsely identifying as autistic). Exclusivity also lends itself to the spread of prejudice and misinformation about the excluded group. (Chapter 8)

Even having read this collection and others, I still am unclear about who exactly is "in," how widely the neurodiversity movement casts its net in defining ND. Does it include just people with autism and other neurodevelopmental conditions like "people with autism, dyspraxia, ADHD," as Garcia states (Chapter 17), or does it further include people with depression, schizophrenia, Tourette's, psychopathology, as Neumeier and Brown suggest in Chapter 14? In this case neurodiversity should be inclusive of neurodegenerative conditions like dementia, and Parkinson's too. The problem is the boundary around who is "in" the ND class and who is "out" is currently not transparent or well-defined.

\section{Representativeness}

Several vocal autistic people and parents have complained that the movement is made up mostly of less impaired individuals who do not represent people with more severe problems [15]. I have also heard people comment at autism conferences that persons in the movement are not representative of most ND adults or children, and are not well-appointed to speak for them. My understanding is that the argument is, broadly, parents of more severely disabled children are keen for treatments to ease their children's condition, whereas the neurodiversity movement is seen as anti-cure [13]. Activists counter that the movement does advocate for supports that mitigate weaknesses associated with autism, arguably focusing more on improving access to reliable communication and certainly more on essential services (which mostly go to those with the highest needs) than most organizations and individuals interested in curing autism.

Those parents supporting more medically-oriented models identify the distress and difficulties associated with neurodevelopmental conditions as impairments [16]. Such difficulties lead to problems in functioning 
and lower quality of life. From this point of view, the conditions that are encompassed by neurodiversity are medical conditions that can and should be cured if possible. Autistic people have also spoken in favor of this more pathologized view: "Many of us aren't high-functioning enough to benefit from depathologizing autism...I still feel autism keeping me from achieving my potential" [17].

It is important to note, however, that many parents are in the movement, including some writing here. The movement allows space for parents and other allies. Sometimes their children, as in the case of Des Roches Rosa, don't have the language skills to engage in conventional activism. So parents are another way in the movement that those who cannot directly represent themselves in formal activism are represented.

Academics have made similar critiques. Ortega [18] argues that so far the movement has been dominated by people diagnosed with Asperger Syndrome and other forms of "high-functioning autism." I have heard a pediatrician-academic dismiss the movement using the same criticism. Casanova, a prominent neurologist writes: "the records that we have at present on neurodiversity are the records of an elite, those that stand at the top...misrepresentation of opinions of the pro-neurodiversity elite as being representative of those at the bottom" [19]. This forms part of a vitriolic attack that claims, "the only thing they have accomplished is the creation of a split in the autism community that allows for themselves and nobody else... Neurodiversity is a social club where many of its participants are non-autistic individuals claiming to be autistics." In another article (also condemned by members of the movement) Jaarsma and Welin make the case that that the neurodiversity doctrine is sensible if it is only applicable to this narrow group "only a narrow conception of neurodiversity, referring exclusively to high-functioning autists, is reasonable" [20].

Activist blogger Hiari, who herself has been given a diagnosis of autism, writes for the critical psychiatry site Mad in America. She issues another stinging critique of the neurodiversity movement [21], writing that the movement amounts to no more than:

A public relations campaign that emphasizes the many positive qualities associated with some presentations of autism — creativity, increased tolerance for repetition, enhanced empathy, superior ability to master content 
in specific subject areas, and exceptional memory—while erasing or minimizing the experiences of autistics who are severely disabled.

People at the vanguard of the neurodiversity movement have often been autistic, as this volume testifies, and they have mobilized through making contact online or on email lists, InLv, and autistics.org being prime examples. The main method of mobilization of the autistic/neurodivergent community therefore inadvertently excludes people who are unable to make contact with each other on computers: "Many on the spectrum can't speak or use a computer" Mitchell asserts [15]. In the current volume, Buckle discusses the efforts that have been made to be as inclusive as possible at Autscape: "we have tried to include some activities that are more accessible to people who don't handle words as well as most of us, with mixed success." She also touches on the practical barriers to achieving full inclusivity and provides a fantastically practical guide to designing autistic-friendly events.

Parents point out that as young children and those with profound intellectual disability cannot advocate for themselves, they as parents must. Activists in the movement counter that parents may have a different agenda to those with lived experience. Activists have stated the case for first-person representation: that elsewhere in society we accept the idea that anyone who speaks for a group should be a member of the group, and by that reasoning any spokesperson for autistic people should be autistic. There are some prominent advocates who themselves or whose child have been diagnosed with intellectual disability or who are non-speaking, some of whom have contributed to this collection. Baggs, who is non-speaking, writes "I'd far rather have Michelle Dawson, Cal Montgomery, Laura Tisoncik, Joelle Smith, or Larry Arnold, speaking on my behalf than these parents" (Chapter 6).

The implication of several writers in the collection is that they are related to other autistic people. Garcia writes of "my autistic brethren" (Chapter 17), and daVanport, "we are linked by a familiar neurology" (Chapter 11). Such statements create a kinship argument: that all autistic people are somehow of one tribe and genetically related, or neurologically similar, so are best qualified to talk about issues that affect the autism community. 
The Science and Technologies scholar Silverman critiques the kinship argument in her book Understanding Autism [13], explaining that autistic advocates' predicate their claim to represent the autism community in "presumed neurological and genetic likeness to other autistic people" (p. 142). Silverman argues such presumed relatedness lends ethical legitimacy and entitlement to be representatives of the whole group, but points out a contradiction if the group embrace genetic and neuro-explanations, but reject genetic research.

\section{Reductionism}

Ortega [18] assesses many of the critiques raised here, and points to the rise of neurological and biologically based explanations for behavior, which replaced the dominant psychoanalytic models of the 1970s. For autism, the "refrigerator mother" theory was interpreted to mean that autism was a reaction to an emotionally deprived upbringing. The shift to a primarily genetic and neurological understandings of autism in the 1980s was ushered in by the pioneering twin studies that provided conclusive evidence of the heritability of autistic traits [22]. The history of autism and how children's mental health and deviance has been variously conceived is covered in many excellent texts, all worth reading [13, 23-25].

There is also bio-medicalization [26]. This process is defined by Conrad as virtually the reverse of neurodiversity: the transformation of everyday human conditions and behaviors into diagnosable, treatable disorders that come to fall under medical jurisdiction [27]. Silverman has cited the increasing diagnosis of autism as an instance of medicalization [13]. Hedgecoe [28] has written about the process of geneticization, through which a condition comes to be understood primarily as genetic. Bumiller has written about this with reference to autism [29].

The rise of neuro-understandings is another example of the way behaviors are now framed as having biological underpinnings. Satel and Lilienfield [30] call this process "Neurocentrism": that is, the tendency to use neurological explanations to explain aspects of a person's behavior, e.g. Shannon Rosa's account of her son: "he was born with his autistic brain" (Chapter 12). 
Both neurocentrism and geneticization have been critiqued as forms of biological reductionism, partly because they de-emphasize the complexity through which behaviors are shaped. A reductionist account would see psychological facts as reducible to neurological facts, which is in turn are reducible to biological facts. One consequence of labeling with a diagnostic category like autism is that autistic people's behavior is attributed to brain difference, rather than being under their control [31,32]. The philosopher of biology Dupré argues against such reductionist accounts of human behavior [33], and opposes the use of causal language.

That genes "cause" autism can be critiqued on many levels. First, behavioral traits which identify autism are exacerbated by the social context and they change over a child's development, so do not imply a fixed state. Some children classified as having autism outgrow their diagnosis, so autism is not necessarily a stable neurological difference throughout the lifecourse [34]. Second, genetic association studies show there is a multi-factorial, complex, genetic predisposition to autism which interacts with epigenetic factors. Third, the environment may alter the development of a person's neurology throughout the lifecourse, whatever their genetics. Fourth, neurology is not fixed but constantly adapted through learning. Dupré argues a better model would be probabilistic causality, where nothing "causes" something else but instead increases the chances of it happening.

Although some activists writing in this collection adopted simpler reductionist models, others show their knowledge of complexity: "Genetic research indicates that at least twenty different genes can signal a predisposition to autistic development" (Seidel, Chapter 7); "the genetic factors involved in autism [are] very complex" (Evans, Chapter 9).

Embracing a more nuanced understanding may be a better reflection of reality, but perhaps neglects the impact causal models can have on the real world. For parents of autistic children, for example, the geneticization of autism has meant thousands of mothers escape the guilt and blame that "refrigerator mother" theory engendered. For neurodiversity activists, neuro-models can be a potent instrument to securing accommodations, services, and rights, and gaining political recognition [18]. 


\section{Medicalization and the Master's House}

More widely, medicalization has been defined as the process through which normal behaviors come to fall under medical jurisdiction [27]. In this sense, the neurodiversity movement seeks to de-medicalize autism, because members have argued that autism is a part of normal human variation and should not be considered as a disorder or in medicalized terms. But at the same time, underpinning these arguments are very biologically/neurologically-grounded models of understanding of difference (e.g. "neuro"-differences, "neuro"-diversity). Arguably, these are part of the medicalized framework. The neurodiversity activists therefore coopt parts of the medical model, whilst espousing broad opposition to the medical model of autism. The whole volume illustrates how a medicalized understanding of autism as a diagnosis of autism spectrum disorder differs from the understanding of autism in the accounts of neurodiversity activists. Contributors describe the medical framework as tending to pathologize people:

We were so used to being misunderstood, patronized and pathologized (Dekker)

The dangers of using a selective pathological description (Baggs)

Undue pathologization of their traits (Seidel)

More general resistance is expressed, e.g. "our community had been segregated by a medical model which insisted on separating us from our natural peers" (Craine, Chapter 19). Such accounts show opposition to medicalization, yet sometimes deploy medicalized rhetoric. In this sense the NDM can be interpreted as using the Master's tools medical narratives] to tear down the Master's house [the medical taxonomic framework], a euphemism used by Lorde [3], a black lesbian feminist.

Lorde's reference to the inability of "the Master's tools to dismantle the Master's house" [3] is a critique of utilizing the rules of those in power. Lorde is arguing that playing their (the Master's) game cannot bring about genuine revolutionary change. ASAN's input into DSM-5, which defines how autism is understood and identified (Chapter 13), was to gain reform not revolution. ASAN chose to engage with the psychiatric system and play 
the rules-adopting the language of science and using scientific citations to communicate their political points to represent the best interests of the autistic community. Kapp and Ne'eman thus provides an excellent counter to the "Master's tools" argument in Chapter 13, showing how ASAN brought about meaningful change. Their tactic of engagement with the establishment is reminiscent of the AIDS activists' strategy of becoming proficient with and co-opting scientific empiricism to become scientific experts and communicate with the scientific establishment [35]. At the same time, they argue that the DSM should openly acknowledge that diagnosis is partly shaped as a political, as well as a scientific process, a point made by others in the academic literature. Aronowitz, for example, argues that symptoms become "a disease" through social and political processes [36]. Acknowledging and encouraging the socio-political nature of psychiatric taxonomy of DSM underlines that autism is an entity that is both constructed and is a neurodevelopmental difference.

It can be pathologizing to be given a diagnosis of disorder. At the same time, the medical diagnosis can act as an explanation of the experience of difference, a rallying point for political action, a tool to unlock resources and services, and a first step in moving toward entering a community. Kapp and Ne'eman acknowledge there is a need for a diagnosis but suggest a middle way might be possible: "We believe that identification of autism should transition to a non-pathological system."

I have questions about one's responsibility for behavior and the way diagnosis (or a diagnostic category) excuses deviant (or poor) behavior as a form of sickness [37]. The problem is a "born this way" narrative deemphasizes personal responsibility, which can be tremendously helpful, but can sometimes be used as an excuse to avoid culpability. If a person was diagnosed with Tourette's, their swearing would be seen as an involuntary aspect of their condition, promoting tolerance and acceptance. On the other hand, what about a psychopathic person who manipulates and exploits others? This behavior also seems to fall under the wider neurodiversity banner, so does the neurodiversity movement require acceptance that the person can't control their behavior, and therefore not culpable or responsible for their behavior? Should neurodivergence be more often considered as a legal mitigating factor? ADHD is strongly associated with 
criminal behavior, for example [38]. Again, perhaps a more nuanced questioning of repercussions of these concepts may be necessary.

\section{Group Think}

A final critique is the accusation that the movement requires conformity. Some complain the movement may engender social conformism through doctrinal thinking that excludes autistic people with diverse viewpoints. Hiari asserts that "The neurodiversity movement epitomizes groupthink" [21], and cites the expulsion of autistics like pro-cure Mitchell and Google engineer Damore (who wrote that male/female disparities can be partly explained by biological difference). I am not sure of the legitimacy of these arguments if Neurodiversity is considered as a political ideology. If it is thought of this way, the neurodiversity movement operates more like a political group, and is entitled to throw out members who express views contrary to the party line. Just because you are female does not make you a feminist.

\section{Conclusion}

These are some of the critiques faced by the neurodiversity movement. Whilst the movement seeks a non-pathologizing form of identity and the autistic activist community and allies have made a unique contribution toward this, this aim may sometimes sit uncomfortably with pragmatic forms that their activism takes.

\section{References}

1. Haraway, D. (1988). Situated knowledges: The science question in feminism and the privilege of partial perspective. Feminist Studies, 14(3), 575-599.

2. Hedges, C. (2018, February 5). The bankruptcy of the American Left. truthdig. Retrieved from https://www.truthdig.com. 
3. Lorde, A. (1983). The master's tools will never dismantle the master's house. In C. Moraga \& G. Anzaldúa (Eds.), This bridge called my back: Writings by radical women of colour (pp. 94-101). New York: Kitchen Table Press.

4. Runswick-Cole, K. (2014). 'Us' and 'them': The limits and possibilities of a 'politics of neurodiversity' in neoliberal times. Disability \& Society, 29(7), 1117-1129.

5. Bailey, A., \& Parr, J. (2003). Implications of the broader phenotype for concepts of autism. In G. R. Bock \& J. A. Goode (Eds.), Autism: Neural basis and treatment possibilities (Vol. 251 of Novartis Foundation Symposia). Chichester, UK: Wiley.

6. Couteur, A., Bailey, A., Goode, S., Pickles, A., Robertson, S., Gottesman, I., et al. (1996). A broader phenotype of autism: The clinical spectrum in twins. Journal of Child Psychology and Psychiatry, 37(7), 785-801.

7. Posserud, M.-B., Lundervold, A. J., \& Gillberg, C. (2006). Autistic features in a total population of 7-9-year-old children assessed by the ASSQ (Autism Spectrum Screening Questionnaire). Journal of Child Psychology and Psychiatry, 47(2), 167-175.

8. Steer, C. D., Golding, J., \& Bolton, P. F. (2010). Traits contributing to the autistic spectrum. PLoS ONE, 5(9), e12633.

9. Larsson, H., Anckarsater, H., Råstam, M., Chang, Z., \& Lichtenstein, P. (2012). Childhood attention-deficit hyperactivity disorder as an extreme of a continuous trait: A quantitative genetic study of 8,500 twin pairs. Journal of Child Psychology and Psychiatry, 53(1), 73-80.

10. Maranon, A. (2018, July 31). [Answer to question:] Why don't neurotypical people understand that many people on the Autism Spectrum (like me) don't know how they feel unless we see an obvious emotional reaction (such as crying)? Retrieved from https://www.quora.com/Why-dont-neurotypical-peopleunderstand-that-many-people-on-the-Autism-Spectrum-like-me-dontknow-how-they-feel-unless-we-see-an-obvious-emotional-reaction-such-ascrying.

11. Griffin, E. M. (2009). A first look at communication theory (7th ed.). New York, NY: McGraw-Hill.

12. Armstrong, T. (2015). The myth of the normal brain: Embracing neurodiversity. Journal of Ethics, 17(4), 348-352.

13. Silverman, C. (2011). Understanding autism: Parents, doctors, and the history of a disorder. Princeton, NJ: Princeton University Press.

14. Horton, H. (2018, May 22). Labour suspends male activist who stood as women's officer 'because he identifies as a woman on Wednesdays'. The Telegraph. Retrieved from https://www.telegraph.co.uk. 
15. Mitchell, J. (2019, January 19). The dangers of 'neurodiversity': Why do people want to stop a cure for autism being found? The Spectator. Retrieved from https://www.spectator.co.uk.

16. Russell, G., Starr, S., Elphick, C., Rodogno, R., \& Singh, I. (2018). Selective patient and public involvement: The promise and perils of pharmaceutical intervention for autism. Health Expectations, 21(2), 466-473.

17. Kansen, P. S. (2016, May 25). What the neurodiversity movement gets wrong about autism. Pacific Standard. Retrieved February 11, 2019, from https:// psmag.com.

18. Ortega, F. (2009). The cerebral subject and the challenge of neurodiversity. BioSocieties, 4(04), 425-445.

19. Casanova, M. (2015, January 5). The neurodiversity movement: Lack of trust (Web log post). Retrieved February 11, 2019, from https:// corticalchauvinism.com/2015/01/05/the-neurodiversity-movement-lackof-trust/.

20. Jaarsma, P., \& Welin, S. (2012). Autism as a natural human variation: Reflections on the claims of the neurodiversity movement. Health Care Analysis, 20(1), 20-30.

21. Hiari, T. (2018, April 8). Neurodiversity is dead. Now what? Mad in America. Retrieved February 11, 2019, from https://www.madinamerica.com.

22. Freitag, C. M. (2007). The genetics of autistic disorders and its clinical relevance: A review of the literature. Molecular Psychiatry, 12(1), 2.

23. Evans, B. (2017). The metamorphosis of autism: A history of child development in Britain. Manchester, UK: Manchester University Press.

24. Nadesan, M. (2005). Constructing autism: Unravelling the 'truth' and understanding the social. London and New York: Routledge.

25. Silberman, S. (2015). Neurotribes: The legacy of autism and the future of neurodiversity. New York, NY: Penguin.

26. Clarke, A. E., Shim, J. K., Mamo, L., Fosket, J. R., \& Fishman, J. R. (2003). Biomedicalization: Technoscientific transformations of health, illness, and U.S. biomedicine. American Sociological Review, 68(2), 161-194.

27. Conrad, P. (2008). The medicalization of society: On the transformation of human conditions into treatable disorders. Baltimore, MD: John Hopkins University Press.

28. Hedgecoe, A. (2001). Schizophrenia and the narrative of enlightened geneticization. Social Studies of Science, 31(6), 875-911.

29. Bumiller, K. (2009). The geneticization of autism: From new reproductive technologies to the conception of genetic normalcy. Signs: Journal of Women in Culture and Society, 34(4), 875-899. 
30. Satel, S., \& Lilienfeld, S. O. (2013). Brainwashed: The seductive appeal of mindless neuroscience. New York: Basic Civitas Books.

31. Farrugia, D. (2009). Exploring stigma: Medical knowledge and the stigmatisation of parents of children diagnosed with autism spectrum disorder. Sociology of Health \& Illness, 31(7), 1011-1027.

32. Singh, I. (2013). Brain talk: Power and negotiation in children's discourse about self, brain and behaviour. Sociology of Health \& Illness, 35(6), 813-827.

33. Dupré, J. (1998). Against reductionist explanations of human behaviour: John Dupré. Aristotelian Society Supplementary Volume, 72(1), 153-172.

34. Fein, D., Barton, M., Eigsti, I. M., Kelley, E., Naigles, L., Schultz, R. T., et al. (2013). Optimal outcome in individuals with a history of autism. Journal of Child Psychology and Psychiatry, 54 (2), 195-205.

35. Epstein, S. (1995). The construction of lay expertise: AIDS activism and the forging of credibility in the reform of clinical trials. Science Technology Human Values, 20(4), 408-437.

36. Aronowitz, R. A. (2001). When do symptoms become a disease? Annals of Internal Medicine, 134(9 Pt 2), 803-808.

37. Conrad, P., \& Schneider, J. W. (1992). Deviance \& medicalization: From badness to sickness. Philadelphia, PA: Temple University Press.

38. Fletcher, J., \& Wolfe, B. (2008). Child mental health and human capital accumulation: The case of ADHD revisited. Journal of Health Economics, 27(3), 794-800.

Open Access This chapter is licensed under the terms of the Creative Commons Attribution 4.0 International License (http://creativecommons.org/licenses/by/ $4.0 /$ ), which permits use, sharing, adaptation, distribution and reproduction in any medium or format, as long as you give appropriate credit to the original author(s) and the source, provide a link to the Creative Commons license and indicate if changes were made.

The images or other third party material in this chapter are included in the chapter's Creative Commons license, unless indicated otherwise in a credit line to the material. If material is not included in the chapter's Creative Commons license and your intended use is not permitted by statutory regulation or exceeds the permitted use, you will need to obtain permission directly from the copyright holder.

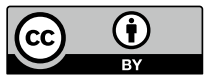

